\title{
ON THE MONITORING OF THE GAS-SOLID FLOWS IN INDUSTRIAL FLUIDIZED BEDS BY USING ELECTRICAL CHARGE SENSORS
}

\author{
M. F. F. de Andrade, \\ and E. dos Reis \\ Instituto Federal de Educação, Ciência e \\ Tecnologia de São Paulo \\ Câmpus São João da Boa Vista \\ Av. Marginal, 585 \\ Bairro Nossa Senhora do Jaguari \\ CEP. $13.871-298$ \\ São João da Boa Vista, SP, Brasil \\ matheus.felix@ifsp.edu.br \\ Received: April 14, 2018 \\ Revised: May 10, 2018 \\ Accepted: May 28, 2018
}

\begin{abstract}
The fluidized bed technology has been used in many industrial processes. It promotes good rates of heat, mass transfer and chemical reaction by generating high level of gas-solid mixture. However, the assurance of quality and efficiency of these processes requires the monitoring of the gassolid flow. For this propose, there are some sensing techniques that allows generating dynamic signals from cold or hot fluidized beds. They are based on pressure fluctuations, acoustic and mechanical vibrations, electrical capacitance and on electrical charges. Electrical charge sensors were proposed originally for measuring the flow velocity in pneumatic conveying. They are composed of one or more metallic electrodes that detect electrical charges in the gas-solid flow, which are generated by particle-particle and particle-wall interaction due to triboelectric effect. In this work, such sensors are explored as a robust and inexpensive solution for the monitoring of industrial fluidized beds. However, since research investments are requested specially on the design of the sensor, concerning the flow quantity of interest and the electrification processes acting on the sensor, in this work different configurations were classified from information in literature, and other were proposed in this work concerning their use with industrial fluidized beds. Although the relation between magnitude of the detected charges and some physical quantities of the flow, such as concentration, is still not clear, other important information can be obtained by analyzing dynamic signals, as velocity or bubbles frequency, or even for identifying of the fluidization regime. It was stated that each configuration, with its own shape and arrangement, can promote or not one or other electrification process by contact, friction or induction and, therefore, each one has a different perception of the flow.
\end{abstract}

Keywords: industrial fluidized bed, electrification process, electrical charge sensor, design

\section{NOMENCLATURE}

$\mathrm{z} \quad$ distance of the sensor above the distributor, $\mathrm{m}$

\section{Greek symbols}

$\phi \quad$ work function, $\mathrm{eV}$

\section{INTRODUCTION}

The gas-solid fluidization occurs when a vertical and ascending gaseous flows through a bed of solid particles, causing the mixture to behave as a fluid (Kunni and Levenspiel, 1991). It generates high level of contact between the particles and the gas, promoting the heat and/or the mass transfer as well as the temperature uniformity. Gas-solid fluidized beds have been used in many industrial processes such as in grain drying, in the catalytic cracking of petroleum (Kunni and Levenspiel, 1991), in combustion and biomass gasification (Sun and Yan, 2016), and more recently for producing new materials based on carbon nanotubes (See and Harris, 2007) and in the production of polyolefins polymers (Wang et al., 2017a).
Fluidization is a complex phenomenon, since it depends on many parameters associated to the gas, the particles and the equipment itself (Crowe, 2006). In literature, many classifications of the so-called fluidization regimes were proposed, which are related to the fluidynamics of the gas-solid flow. However, in terms, when the gas flow rate is increased from zero, the flow regime changes from that one called of fixed bed to the circulating bed. Along this, one can observe a number of intermediary regimes, as the incipient or smooth one, the bubbling, the churn, the slug and the turbulent regime (Kunni and Levenspiel, 1991). Each one has advantages and disadvantages in relation to the different industrial processes. Therefore, the development of techniques for effective monitoring of the gas-solid flow in industrial fluidized bed for further control is necessary, ensuring the efficiency and quality of the processes.

Many techniques for monitoring the fluidynamics of gas-solid fluidized beds are discussed in the literature (Sun and Yan, 2016). Some techniques allow acquiring dynamic related to the flow, such as those based on pressure fluctuations, on acoustics and mechanical vibrations, on electrical 
capacitance and on electrical charges. None of them requests for special safety procedures as X-ray or gamma ray, and all of them have a relatively low complexity for installation and, therefore, they all have some potential for application in cold or in hot industrial fluidized beds. Some techniques may be invasive or noninvasive, which means that the sensor can keep or not contact with the flowing materials. They also can be intrusive or nonintrusive, which means that the sensor can disturb or not the flow. Table 1 summarizes information from some recent works in the literature.

Table 1. Information from sensing techniques from recent works in the literature.

\begin{tabular}{|c|c|c|c|c|}
\hline Technique & Citation & $\begin{array}{l}\text { Material of the } \\
\text { bed }\end{array}$ & Type of sensor & $\begin{array}{l}\text { Material } \\
\text { of the } \\
\text { pipe }\end{array}$ \\
\hline \multirow{2}{*}{$\begin{array}{l}\text { Pressure } \\
\text { Fluctuations }\end{array}$} & Schaffka et al. (2015) & $\begin{array}{c}\text { Air and } \\
\text { aluminum beads }\end{array}$ & $\begin{array}{l}\text { Pressure tap in the plenum (invasive } \\
\text { and not intrusive) }\end{array}$ & Acrylic \\
\hline & Wang et al. (2017b) & Air and sand & $\begin{array}{l}\text { Pressure tap in the plenum (invasive } \\
\text { and not intrusive) }\end{array}$ & Acrylic \\
\hline $\begin{array}{l}\text { Acoustic and } \\
\text { Vibrational }\end{array}$ & Li et al. (2011) & $\begin{array}{l}\text { Air and glass } \\
\text { beads }\end{array}$ & $\begin{array}{l}\text { Micro-sensor installed in the outer } \\
\text { wall near to the bed region (non- } \\
\text { invasive and non-intrusive) }\end{array}$ & Acrylic \\
\hline \multirow[b]{2}{*}{ Capacitive } & $\begin{array}{l}\text { Weber and Mei } \\
(2013)\end{array}$ & $\begin{array}{l}\text { Air and glass } \\
\text { beads }\end{array}$ & $\begin{array}{l}\text { Electrodes installed on the external } \\
\text { wall of the pipe, in the bed region } \\
\text { (non-invasive and non-intrusive) }\end{array}$ & Acrylic \\
\hline & $\begin{array}{l}\text { Chandrasekera et al. } \\
(2015)\end{array}$ & $\begin{array}{l}\text { Air and silica- } \\
\text { alumina catalyst }\end{array}$ & $\begin{array}{l}\text { Electrodes ( } 12 \text { ones) installed on the } \\
\text { outer external surface of the pipe, in } \\
\text { the bed region (non-invasive and non- } \\
\text { intrusive) }\end{array}$ & Acrylic \\
\hline \multirow{5}{*}{$\begin{array}{l}\text { Electrical } \\
\text { Charges }\end{array}$} & Zhou et al. (2013) & Air and $\mathrm{LDPE}^{\mathrm{a}}$ & $\begin{array}{l}\text { Metallic and covered rod installed } \\
\text { through the wall and into the bed } \\
\text { (invasive and intrusive) }\end{array}$ & Acrylic \\
\hline & Chen et al. (2014) & $\begin{array}{c}\text { Air and steel } \\
\text { particles }\end{array}$ & $\begin{array}{l}\text { Pin installed in the wall (invasive and } \\
\text { nonintrusive) }\end{array}$ & $\begin{array}{c}\text { Not } \\
\text { informed }\end{array}$ \\
\hline & Zhang et al. (2016) & $\begin{array}{l}\text { Air and particles } \\
\text { of polyethylene }\end{array}$ & $\begin{array}{l}\text { Ring on the external surface of the } \\
\text { pipe (non-invasive and non-intrusive) }\end{array}$ & Acrylic \\
\hline & Yang et al. (2017) & $\begin{array}{l}\text { Air and } \mathrm{LDPE}^{\mathrm{a}} \\
\text { or } \mathrm{PP}^{\mathrm{b}}\end{array}$ & $\begin{array}{l}\text { Ring installed on the external surface } \\
\text { of the pipe (non-invasive and non- } \\
\text { intrusive) }\end{array}$ & Acrylic \\
\hline & Zhang et al. (2017) & Air and sand & $\begin{array}{l}\text { Grid of wires installed in the bed } \\
\text { (invasive and intrusive) }\end{array}$ & Acrylic \\
\hline
\end{tabular}

${ }^{\mathrm{a}}$ Low-density polyethylene (LDPE).

${ }^{\mathrm{b}}$ Polypropylene (PP).

The pressure fluctuation technique has good potential for application in hot and cold industrial equipment, mainly due to easy way for installation of pressure taps and the transducers, which are nowadays capable of acquiring dynamic signals with precision, although one must consider that dynamic pressure measurement systems requires some special attention (de Gaspari and dos Reis, 2007). Pressure signals are generally acquired at the plenum just below the distributor, since this option prevents clogging of the taps and even contamination of the sensor element (van Ommen and Mudde, 2007). However, the distributor itself can act as a low-pass filter, cutting-off higher frequency components and distorting the signal related to the gas-solid flow in the fluidized bed (van Ommen and Mudde, 2007). In addition, the interpretation of the acquired signals is still a relatively complex task.

A microphone or an accelerometer can be installed in a strategic position near the fluidized bed, generating dynamic signals from gas-solid flow. Such acoustic or vibrational sensors are usually made of silicon or quartz. They are not suitable for operation at temperatures as higher as $500{ }^{\circ} \mathrm{C}$, and they are susceptible to industrial noise that occurs in the same spectrum region of the fluidized bed signal. Therefore, their potential for industrial applications is still low.

Capacitive sensors can be used for monitoring cold or hot fluidized beds. The sensor is generally nonintrusive and is composed of one or more electrodes that comprise a capacitor, where the gassolid mixture is a part of the dielectric medium around them. In this technique, the transducer operates with higher excitation frequencies of $1 \mathrm{MHz}$ or more, which can eventually generate undesired electrical couplings. Besides the walls of an industrial equipment are generally of steel that does not allow 
electrical fields to cross, the electrodes of the sensor must be mounted in contact with the flow (Sun and Yan, 2016). Alternatively, a dielectric material, a resistant polymer section can be used at low temperatures or a ceramic material at high temperatures, must be used to keep the electrodes on the external wall. However, a substantial increase of complexity of the system can occurs. Electrical Capacitance Tomography Systems (ECT) can be used for generating tomographic images from the flow (Chandrasekera et al., 2015).

Originally, electric charge sensors were proposed for measuring the flow velocity in pneumatic conveying pipes. More recently, they have been explored for application in fluidized beds (Sun and Yan, 2016, Shi et al., 2017). Basically, they detect the electrical charges on the surface of the flowing particles, generated by particle-particle and friction due to movement of solid particles in the flow (Xie et al., 2001). This means that, when the particulate material is handled, the particles become naturally charged (Matsusaka et al., 2010), generating distributions of electrostatic potential into the fluidized bed that depends on the gas-solid fluidynamics itself (Chen et al., 2007, Zhou et al., 2013). They operate with signals of lower frequency components below $100 \mathrm{~Hz}$, and have potential for monitoring fluidized beds even at high temperatures. They can be a robust and low-cost solution for monitoring industrial fluidized beds, which motivated the proposal of this work. On this, there are two subjects still requesting for research investments: sensors and transducers design, and data acquisition and signal analysis.

One must regard that the monitoring of twophase flows by analyzing the acquired dynamic signals does not depend exclusively on the amplitude of the signal, which may vary due to the high number of involved variables, but important information can be extracted from how the signals vary over the time (Ren et al., 2001, Jie et al., 2017).

Consequently, this work is aimed to contribute on the perspective of using electrical charge sensor for monitoring industrial fluidized beds, focusing on the design of such sensors and on their possible configurations subject to the different electrification processes.

\section{ELECTRIFICATION PROCESSES IN GAS- SOLID FLUIDIZED BEDS}

From the equilibrium condition, solid bodies can acquire electric charge through the so-called electrification processes. When two solid objects of different materials are placed in contact, electrical charges are transferred from one to other by contact electrification. This charge transfer occurs along a period until the saturation, as shown in Fig. 1 (a).

When both bodies are of different metallic materials, the amount of charge transferred depends on the shape of the bodies and on the difference in the working function of each one, which is defined as the minimum energy necessary to remove an electron from the outer layer on the metal surface (Bailey, 1984).

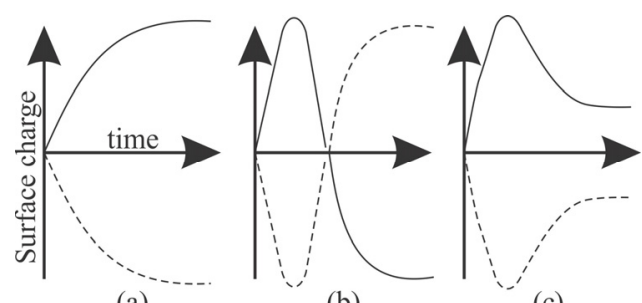

(a)

(b)

(c)

Figure 1. Charge transfer along the time: (a) by contact, (b) by friction, and (c) by friction with saturation. Adapted from Bailey (1984).

Table 2 presents values of the work function, $\phi$, for materials commonly found in industrial environments. For example, if a fluidized bed equipment has wall of $316 \mathrm{~L}$ stainless steel, the contact electrification process will be more favorable if the particles are of lead, and will be less favorable if the particles are also of $316 \mathrm{~L}$ stainless steel. The work function is not a property of the material, but it is strongly dependent on the surface condition. Therefore, in practice, impurities or oxides on the surfaces also affect the transfer of electrical charge by contact.

Table 2. Work function for some materials.

\begin{tabular}{|c|c|c|c|}
\hline Metals & $\phi[\mathrm{eV}]$ & Insulators & $\phi[\mathrm{eV}]$ \\
\hline Aluminum & $4.53^{\mathrm{a}}$ & Glass & $5.32^{\mathrm{a}}$ \\
\hline Copper & $5.11^{\mathrm{a}}$ & Nylon 66 & $5.61^{\mathrm{a}}$ \\
\hline Iron & $4.50^{\mathrm{b}}$ & PTFE & $5.80^{\mathrm{a}}$ \\
\hline Lead & $4.25^{\mathrm{b}}$ & Teflon & $4.26^{\mathrm{a}}$ \\
\hline Platinum & $5.64^{\mathrm{b}}$ & Polystyrene & $5.48^{\mathrm{a}}$ \\
\hline Silver & $4.66^{\mathrm{a}}$ & Acrylic & $5.52^{\mathrm{a}}$ \\
\hline 316L stainless steel & $5.05^{\mathrm{b}}$ & PVC & $4.85^{\mathrm{a}}$ \\
\hline
\end{tabular}

${ }^{a}$ Trigwell et al. (2001), data measured in air and at room temperature.

${ }^{\mathrm{b}}$ Lide (2008).

When one body is made of an electrically insulating material, because the mobility of the charges in the contact region is restricted, the charge transfer is also dependent on the electrical properties of this insulation material. For example, among the materials in Table 1, if the fluidized bed equipment is of $316 \mathrm{~L}$ stainless steel, contact electrification will be more favored if the particles are of Teflon (Matsusaka et al., 2010). Yet, when both bodies are made of electrically insulating materials, the net charge transfer will be even more restricted than the previous case (Matsusaka et al., 2010). Moisture content of porous materials, as biomass, or other particulate materials also affects the contact electrification, since ionic charge transfer can also be present (Nomura et al., 2003). 
As shown in Fig. 1 (a), in any of the cases of contact electrification, there is a time interval necessary to reach the saturation level, when the transfer of charges ceases. However, when the contact time is short and lower than that required for saturation, there occurs a process called of impact electrification (Yoshida et al., 2006, Watanabe et al., 2007) as described in literature.

Another electrification process occurs when two bodies of distinct materials are rubbed together, called of friction electrification. Unlike the contact electrification, in this case the charge transfer over time occurs according to Figs. 1 (b) or (c), whereby the net charge transferred depends on the mechanical energy involved, the contact time, and even the presence of heat. Therefore, the intensity of this phenomenon can vary widely. There is a triboelectric series with information on the polarity of the net charge in each body. However, there are situations where polarity can differ from the predicted (Kanazawa et al., 1995). In addition, the adhesion of one material to the other may also influence the process of frictional electrification (Matsusaka et al., 2010).

The electrification by contact, by friction and by impact are phenomena that occur simultaneously in industrial processes, being very difficult to study them separately. Due to this, the term triboelectric charging is used to refer to these three processes in general (Matsusaka et al., 2010).

A fourth electrification process is called of electrical induction, in which the charge transfer occurs without direct contact due to the presence of electrical fields (Sun and Yan, 2016). It occurs on a metallic body connected to a fixed electrical potential, usually the ground one, by a wire. When one face of the body is subject to electrical fields due to charge particles, for example, the charge unbalance on the opposite side are cancelled then by opposite charges coming from the ground. The information from the induction electrification can be registered by measuring the electric current through the wire (Zhang, 2016).

On gas-solid flows, particulate solids are subject to triboelectric charging when handled in industrial processes. Therefore, if fluidized bed is started with particles of a single material and with all elements in electrical equilibrium, the particles are initially charged by friction with the internal walls of the equipment (Bailey, 1984). Then, these charges are transferred to other particles or to other parts of the equipment by contact/impact electrification due to the flow. If the bed is composed of particles of more than one material, a portion of electrification should be due to the particle-particle triboelectric effect (Forward et al., 2009). The charged particles can form agglomerates, or even accumulate on the surface of insulating materials, which can affect the fluidynamics itself (Ciborowski and Wlodarski, 1962). In addition, the presence of gases around the bodies can also affect the electrical charge, since their molecules can also extract amounts of electrons at higher energy levels from the surfaces, even if small. Therefore, electrification is a complex phenomenon in fluidized beds.

\section{ELECTRICAL CHARGE SENSORS AND GAS- SOLID FLUIDIZED BEDS}

Differently of pneumatic conveying, the quantities of gas-solid flow generally assume a more complex distribution in fluidized beds. For example, the vertical component of velocity of the particles can be ascending or descending (Sun and Yan, 2016, Zhang et al., 2016).

Electric charge sensors can be invasive or noninvasive, as they can be intrusive or non-intrusive depending on the sensor configuration. They have been studied with electrodes mounted on a nonconductive pipe (acrylic) as riser, under laboratory and cold conditions, as shown in the right column of Table 1. However, industrial equipment has generally walls made steel, and can operate at high temperatures and pressures, which becomes them inadequate for such application in literature. In fact, they should be invasive for operation with industrial fluidized beds.

Figure 2 is presents a proposal for classifying the configurations of electrical charge sensors. There are four configurations: pin in (a), ring in (b), rod in (c), and plate in (d). This last one was not found in literature. They are represented as installed in a vertical round pipe section with a fluidized bed of particles. Although a fluidized bed can have other shapes in practice, as square or rectangular, the round shape was adopted by practicality.

All configurations of Fig. 2 are invasive, however, while (a) and (b) are non-intrusive, (c) and (d) are intrusive. While non-invasive sensors are based essentially on the electrical induction, invasive sensors may have all the electrification processes acting simultaneously. Electrical charging occurs essentially by induction at the metallic surface of the sensor, or also by triboelectric effect depending if there is or not direct contact between the metal and the particles, as discussed in the item 4. Therefore, their sensitivity will depend on all active electrification processes, as discussed in the item 4 . Besides each configuration in Fig. 2 have a unique perception of the flow also due to their arrangement in relation to the particles, which can be local in a small region of the flow if the sensing area is small, or global in a volume of the riser. Yet, if the triboelectric effect is present, it can be several times greater than the induction effect, and the local sensitivity can be improved. Otherwise, if only the induction effect is present, one can improve the global sensitivity. 


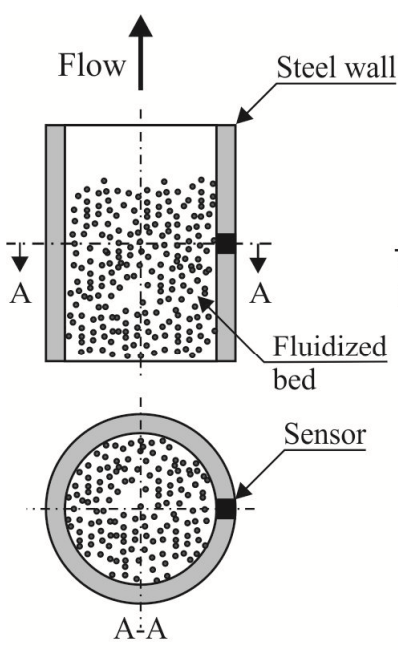

(a)
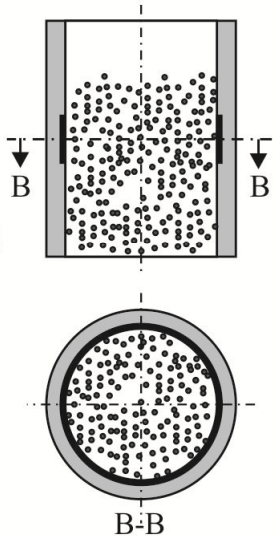

(b)
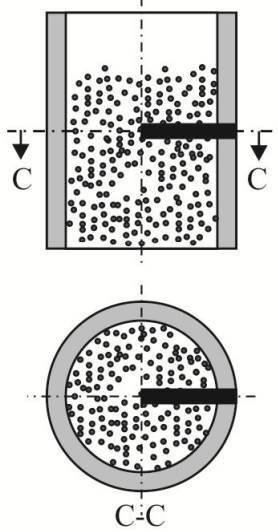

(c)
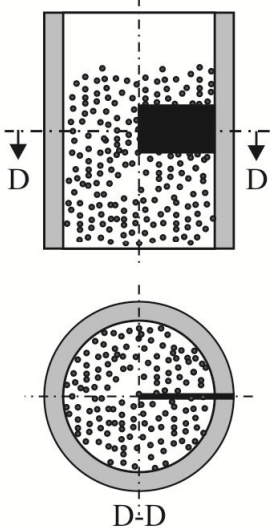

(d)

Figure 2. Configurations electrical charge sensors: (a) pin, (b) ring, (c) rod, and (d) plate.

Still on the shape of each sensor as shown in Fig. 2, while the pin sensor has a local sensitivity to the particles, the ring sensor has high sensitivity around the entire perimeter. Rod and plate ones should have high sensitivity also to the charged particles in the central region of the bed. However, because the plate configuration (d) have a high width to thickness ratio, the global sensitivity should be improved, but the tangential component of the flow velocity can be affected, which can be or not important to the industrial process.

The sensor can be designed as having one or more electrodes that can be of the same or of different configurations. For example, several pins around the perimeter of the pipe, or a ring and a plate, where mutual cross talk can be desired or not. Therefore, concerning the requested characteristics of the process and the monitoring goals, the engineer can choose the most suitable configuration, which also leads to the quantity of interest that should be, for example, the local or volumetric concentration, the local or averaged velocity of particles in one or other direction, the size, distribution and frequency of bubbles or slug, etc. However, even the relationship between such quantities and the electrical charge sensors, as the non-linear characteristic of this type of system that requires the application of compatible signal analysis techniques, are still subjects that request for research investments.

\section{PERSPECTIVES FOR THE DESIGN OF ELECTRIC CHARGE SENSORS FOR MONITORING INDUSTRIAL GAS-SOLID FLUIDIZED BEDS}

From the main configurations shown in Fig. 2, Fig. 3 shows alternatives for the design of electric charge sensors concerning the electrification processes that can act on the sensor. In the left-hand corner, a diagram of a fluidized bed with a distributor is shown. An electric charge sensor would be installed at a distance $\mathrm{z}$ above the distributor, and whose external steel tube, indicated in gray, is connected to the ground potential as in industrial installations. Since the fluid dynamics changes from the distributor (Shi et al., 2017), one must also determine the desired position $\mathrm{z}$.

There are two types of particles in the flow: induction and contact particles as shown in Fig. 3 (a). The induction particles are always in greater number than the contact particles. The perception of the sensor in relation to the induction particles occurs exclusively by the formation of electric fields, whose intensity depends on the electrical charges of each particle in time instant, which intensity is inversely on the square of the distance between them and the surface of the sensor. Therefore, while the induction can promote the general perception of the particles depending on the shape of the sensor, the triboelectric effect promotes a local perception of what occurs very near to its surface.

In Fig. 3, there are three columns with constructive details of each arrangement, according to configurations in Fig. 2: in (a) and (b) for the pin, (c) and (d) for the ring, (e), (f) and (g) for the rod, and (h) and (i) for plate configuration. In all of them, the metallic region of the sensor is indicated in black. The arrangements (a), (c), (e) and (h) in the first column are similar to that of Fig. 2, with the electrodes keeping direct contact with the flowing particles and, therefore, both induction and triboelectric charging processes act on the sensor in a conjugated way. However, the arrangements (b), (d), (f) and (i) in the second column have an electrically insulating material coating the metal of the sensor, which allow only induction charging act on the sensor. The triboelectric effect can occur on the surface of the insulating material, which eventually 
can accumulate charges on its surface in contact with the particles, and which cause induction charging on the metallic part of the sensor. Although the last ones are influenced indirectly by the triboelectric effect, it can be many times lower than if direct contact occurs, therefore, induction can improve the perception of the sensor to particles farther from the wall.

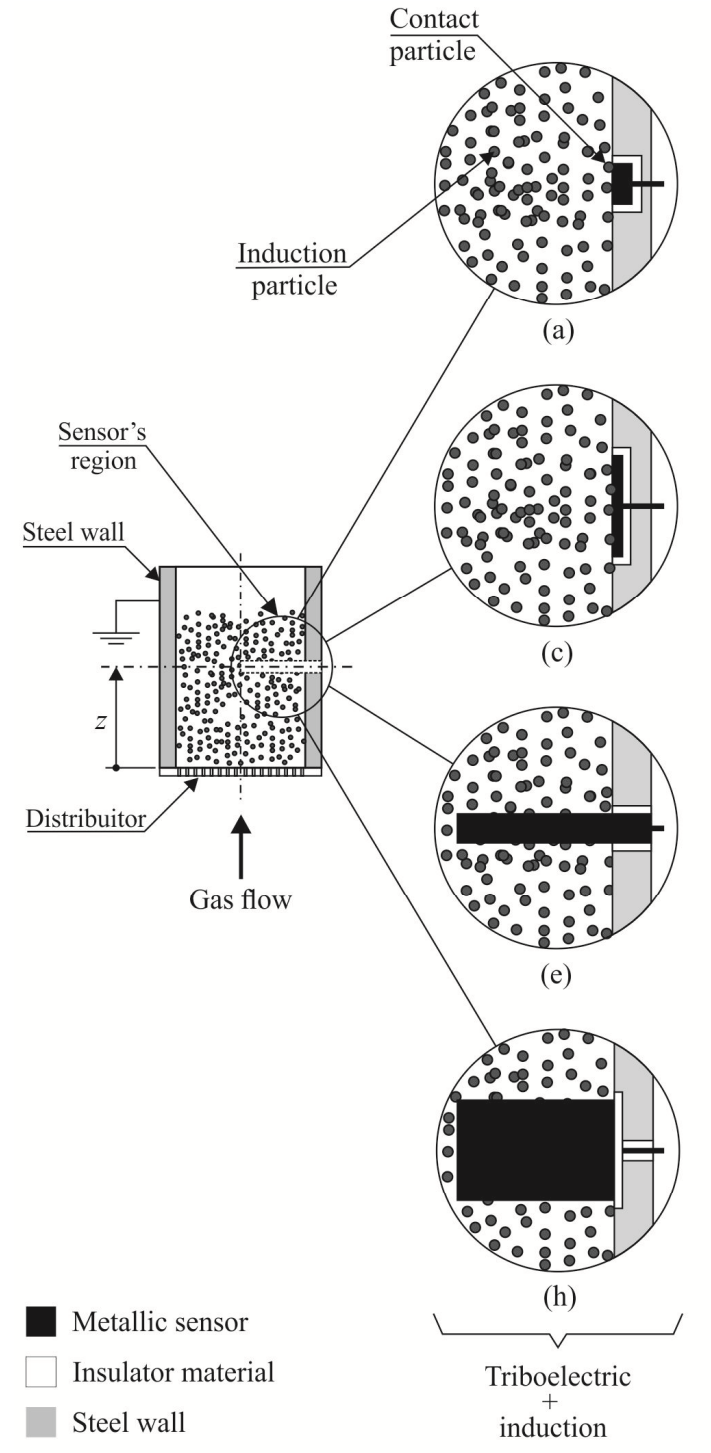

Among all arrangements shown in Fig. 3, there must be always be a layer of insulation between the metal of the sensor and the wall of the steel pipe, which avoids the electrical potentials generated on the sensor to be drained by the ground.

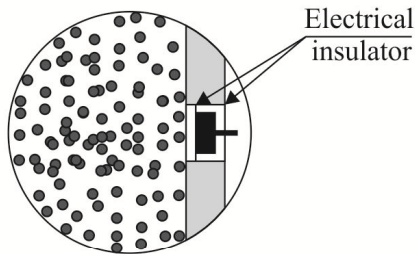

(b)

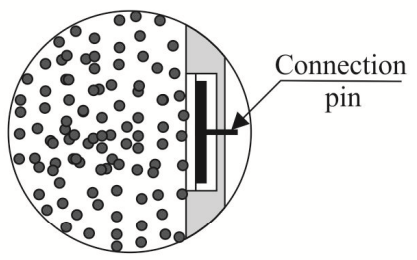

(d)

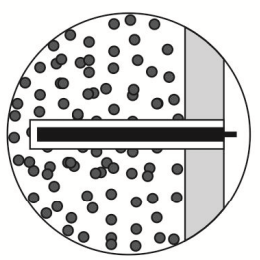

(f)

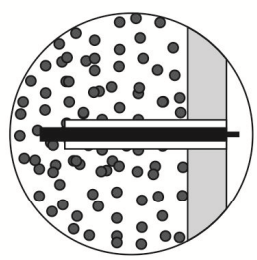

(g)

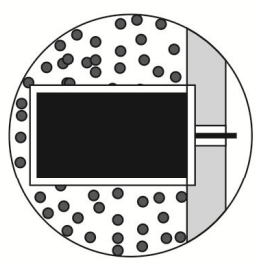

(i)

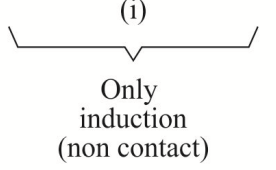

Figure 3. Alternative arrangements from the main configurations in Fig. 2.

The arrangement shown in Fig. $3(\mathrm{~g})$ has a pin partially coated with insulating material, with its tip directly in contact with the particles. Therefore, in this arrangement, only electrical induction occurs in the coated section, while in tip both induction and triboelectric charging are present. If desired, the sensitivity can be kept only at the tip for local measurements into the fluidized bed. This can be made by also coating the insulating material with a layer of a conductive material, which must be also grounded and connected to the steel wall (Zhou et al., 2013).
Finally, one must also consider safety requirements, and even abrasion and corrosion on the sensor, especially in intrusive configurations, for monitoring industrial fluidized beds by using electrical charge sensors.

\section{CONCLUSIONS}

Technologies for monitoring are aimed to reduce costs and improve the processes quality, and their development based in electrical charge sensors have been recently gained attention, according to 
literature. Such research effort can be divided in two main subjects: the design and assembly of a sensor that can generate signals of interest related to the flow dynamics into the bed, and the application of suitable signal analysis techniques that can extract information from the acquired dynamic signals. In this work, the design of the electric charge sensor was addressed, and the presented information to state the following conclusions:

1. the monitoring of two-phase flows by analyzing the acquired dynamic signals does not depend exclusively on the amplitude of the signal, which may vary due to the high number of involved variables, but important information can be extracted from how the signals vary over the time;

2. because the walls of an industrial fluidized bed equipment are generally of steel, the electrical charge sensor should be invasive preferably, meaning that they must be in direct contact with the particles;

3. electrical charge sensors can be classified in four main configurations: pin, ring, rod and plate, and each one with a singular perception to gas-solid flow; 4. a number of alternative arrangements can be proposed from the main configurations. They can promote one or other electrification process acting on the sensor (by induction and by triboelectric effect), which can improve the local or the global sensitivity of the sensor;

5. concerning the requested characteristics of the process and the monitoring goals, the engineer must begin the design by choosing the most suitable arrangement for the sensor, which can compose of one or more electrodes of the same or of distinct configurations.

\section{ACKNOWLEDGEMENTS}

The financial support of the Federal Institute of Education, Science and Technology of São Paulo (IFSP), by the Pro-equipment Institutional Program, "Edital n' 92/2014", is deeply appreciated.

\section{REFERENCES}

Bailey, A. G., 1984, Electrostatic Phenomena during Powder Handling, Powder Technology, Vol. 37, pp. 71-85.

Ciborowski, J., and Wlodarski, A., 1962, On Electrostatic Effects in Fluidized Beds, Chemical Engineeing Science, Vol. 17, No. 1, pp. 23-32.

Chandrasekera, T. C., Li, Y., Moody, D., Schnellmann, M. A., Dennis, J. S., and Holland, D. J., 2015, Measurement of Bubble Sizes in Fluidised Beds Using Electrical Capacitance Tomography, Chemical Engineering Science, Vol. 126, pp. 679687.

Chen, A., Bi, H. T., and Grace, J. R., 2007, Charge Distribution Around a Rising Bubble in a Two-Dimensional Fluidized Bed by Signal Reconstruction, Powder Technology, Vol. 177, pp.
113-124.

Chen, Z., Tang, X., Hu, Z., and Yang, Y., 2014, Investigations into Sensing Characteristics of Circular Thin-Plate Electrostatic Sensors for Gas path Monitoring, Chinese Journal of Aeronautics, Vol. 27, No. 4, pp. 812-820.

de Gaspari, C. A., and dos Reis, E., 2007, On Measuring Dynamic Pressure in Muntiphase Flows, in: Proceedings of the 19th International Congress of Mechanical Engineering COBEM 2007, Brasília, Brasil.

Forward, K. M., Lacks, D. J., and Sankaran, M., 2009, Triboelectric Charging of Granular Insulator Mixtures Due Solely to Particle-Particle Interactions, Industrial Engineering Chemistry Research, Vol. 48, pp. 2309-2314.

Jie, X., Qinghai, L., Zhongchaoab, T., and Yanguoa, Z., 2017, Characterization of the Flow in a Gas-Solid Bubbling Fluidized Bed by Pressure Fluctuation, Chemical Engineering Science, Vol. 174, pp. 93-103.

Kanazawa, S., Ohkubo, T., Nomoto, Y., and Adachi, T., 1995, Electrification of a Pipe Wall during Powder Transport, Journal of Electrostatics, Vol. 35, pp. 47-54.

Kunii, D., and Levenspiel, O., 1991, Fluidization Engineering, John Wiley \& Sons, New Jersey, 2nd edition.

Li, Yan-qin, Grace, J. R., Gopaluni, R. B., Bi, H., Lim, C. J., and Ellis, N., 2011, Characterization of Gas-Solid Fluidization: a Comparative Study of Acoustic and Pressure Signals, Powder Technology, Vol. 214, pp. 200-210.

Lide, D. R., 2008, CRC Handbook of Chemistry and Physics: 89th edition 2008-2009. CRC Press.

Matsusaka, S., Maruyama, H., Matsuyama T., and Ghadiri, M., 2010, Triboelectric Charging of Powders: a Review, Chemical Engineerin Science, Vol. 65, pp. 5781-5807.

Nomura, T., Satoha, T., and Masudab, H., 2003, The Environment Humidity Effect on the TriboCharge of Powder, Powder Technology, Vol. 135, pp. 43-49.

Ren, J., Mao, Q., Li, J., and Lin, W., 2001, Wavelet Analysis of Dynamic Behavior in Fluidized Beds, Chemical Engineering Science, Vol. 53, No. 3, pp. 981-988.

Schaffka, F. T. S., da Silva, C. A. M., Janzen, F. C., and Parise, M. R., 2015, Monitoring the Fluidization Quality in a Fluidized Bed Paste Drying Using Pressure Fluctuation Measurements, in: Proceedings of the 23rd International Congress of Mechanical Engineering COBEM 2015, Rio de Janeiro, Brasil.

See, C. H., and Harris, A. T., 2007, A Review of Carbon Nanotube Synthesis via Fluidized-Bed Chemical Vapor Deposition, Industrial \& Engineering Chemistry Research, Vol. 46, pp. 9971012.

Shi, Q., Zhang, Q., Han, G., Zhang, W., Wang, 
J., Huang, Z., Yang, Y., Yang, Y., Wu, W., and Yan, Y., 2017, Simultaneous Measurement of Electrostatic Charge and its Effect on Particle Motions by Electrostatic Sensors Array in Gas-Solid Fluidized Beds, Powder Technology, Vol. 312, pp. 29-37.

Sun, J., and Yan, Y., 2016, Non-Intrusive Measurement and Hydrodynamics Characterization of Gas-Solid Fluidized Beds: a Review, Measurement Science and Technology, Vol. 27, No. 11, pp. 112001-31.

Trigwell, S., Grable, N. Yurteri, C. U., and Mazumder, M. K., Effects of Surface Properties on the Tribocharging of Polymer Powder as Applied to Industrial Processes, in: Proceedings of the Industry Applications Conference, 2001, Thirty-Sixth IAS Annual Meeting. Conference Record of the 2001 IEEE, Chicago, IL, USA.

van Ommen, J. R., and Mudde, R. F., 2007, Measuring the Gas-Solids Distribution in Fluidized Beds: a Review, in: Proceedings of The 12th International Conference on Fluidization, Vancouver, Canada.

Xie, C. G., Stott, A. L., Huang, S. M., Plaskowski, A., and Beck, M. S., 1989, Mass-Flow Measurement of Solids Using Electrodynamic and Capacitance Transducers, Journal of Physics E: Scientific Instruments, Vol. 22, No. 9, pp. 712-719.

Wang, H-t., Huang, Z-1., Liao, Z-w., Jiang, B-b., Wang, J-d., Yang, Y-r., Han, G-d., and Yang, B-z., 2017a, From Noise to Information: a New Technology of Olefin Polymerization Fluidized Bed Reactor Based on Acoustic Emission, Journal of Zhejiang University-Science A (Applied Physics \& Engineering), Vol. 18, pp. 245-255.

Wang, J., Zhong, W., and Zhang, H., 2017b, Characterization of Flow Regimes in Fluidized Beds by Information Entropy Analysis of Pressure Fluctuations, The Canadian Journal of Chemical Engineering, Vol. 95, pp. 578-588.

Watanabe, H., Ghadiri, M., Matusuyama, T., Ding, L. D., Pitt, K. G. Y. G., Murayama, S., Matsusaka, S., and Masuda, H., 2007, Triboelectrification of Pharmaceutical Powders by Particle Impact, International Journal of Pharmaceutics, Vol. 334, pp. 149-155.

Weber, J. M., and Mei, J. S., 2017, Bubbling Fluidized Bed Characterization Using Electrical Capacitance Volume Tomography (ECVT), Powder Technology, Vol. 242, pp. 40-50.

Yang, Y., Zhang, Q., Zi, C., Huang, Z., Zhang, W., Liao, Z., Wang, J., Yang, Y., Yan, Y., and Han, G., 2017, Monitoring of Particle Motions in GasSolid Fluidized Beds by Electrostatic Sensors, Powder Technology, Vol. 308, pp. 461-471.

Yoshida, M., Ii, N., Shimosaka, A., Shirakawa, Y., and Hidaka, J., 2006, Experimental and Theoretical Approaches to Charging Behavior of Polymer Particles, Chemical Engineering Science, Vol. 61, pp. 2239-2248.

Zhang, W., Yan, Y., Yang, Y., and Wang, J.,
2016, Measurement of Flow Characteristics in a Bubbling Fluidized Bed Using Electrostatic Sensor Arrays, IEEE Transactions on Instrumentation and Measurement, Vol. 65, No. 3, pp. 703-712.

Zhang, S., Yan, Y., Qian, X., and Hu, Y., 2017, Measurement of Charge Distributions in a Bubbling Fluidized Bed Using Wire-Mesh Electrostatic Sensor, IEEE Transactions on Instrumentation and Measurement, Vol. 66, No. 3, pp. 522-534.

Zhou, Y., Ren, C., Wang, J., Yang, Y., and Dong, K., 2013, Effect of Hydrodynamic Behavior on Electrostatic Potential Distribution in Gas-Solid Fluidized Bed, Powder Technology, Vol. 235, pp. 917. 